\title{
GREEN HOSPITALS, GREEN HEALTHCARE
}

\author{
PILAR CHÍAS \& TOMÁS ABAD \\ School of Architecture, University of Alcala, Spain.
}

\begin{abstract}
Concepts related to 'green health' and 'green hospitals' are rapidly changing and varying their scopes towards wider perspectives. Environmental health considers the natural, built and social environments, implying a better understanding of the way they impact on health, and accepting that the built environment plays an important role in it. On the one hand, impacts of building design, construction, operation and management of hospitals on environment and health are currently accepted. On the other hand, hospitals are complex systems, where changes are neither fast nor easily performed. In order to achieve a green healthcare system, a deep knowledge of its strengths and weaknesses is needed, as well as of the internal dynamics. According to this target, our research focuses on the identification of opportunities for improving the existing health facilities according to the new concepts related to green hospitals. We deal with the study of various aspects as the site and its environment, better access, efficient management of resources (particularly water and energy), waste reduction, use of renewable and low emission materials, as well as all factors in design that can improve the users' wellness. Some decisions must be taken at the early phases of planning, design, and construction, while other can be reached when hospitals are already operating. In addition, some decisions affect the buildings and their sites (the ecological footprint of the facility), while other extend to the neighbouring communities (districts, and municipal infrastructures and services) in order to diminish the risks, and to protect natural resources. Decisions can even affect wider ranges (as supplies and purchasing, for instance) and can help the efficient management while reducing the environment degradation. The proposed case study is University Hospital Príncipe de Asturias in Alcalá de Henares.
\end{abstract}

Keywords: evidence-based design, green building, healthcare facilities, Spain, sustainable design, therapeutic environment

\section{INTRODUCTION}

Healthcare facilities should provide a therapeutic environment in which the overall design of the building and its site contribute to the process of healing, rather than simply being a place where treatment takes place [1].

This change of paradigm implies that both healthcare planning and design processes must be broad enough to include not only the issues surrounding the treatments, but also the promotion of health and prevention of disease by creating a safe and therapeutic care environment. According to the World Health Organization [2], 'environments are considered therapeutic (with healing qualities) when there is direct evidence that a design intervention contributes to improved patients outcomes'.

On the other hand, impacts of building design, construction, operation, and management of hospitals on environment and health are currently accepted. Consequently our research deals with the adequacy of existing healthcare facilities to the new healthcare concepts as feel-at-home, green hospitals, or the enlargement of out-patient clinic and ambulatory care and surgery to the detriment of in-patient facilities due to shorter lengths of stay. The hospital of the future is already here, leading the major clinical and educational innovations, and therefore, healthcare indoor and outdoor spaces must be designed accordingly. To provide the guidelines for building or renovating 'safe by design' [3] is our main target.

But hospitals are complex systems, where changes are neither fast nor easily performed. In order to achieve a green healthcare system, a deep knowledge of its strengths and weaknesses is needed, as well as of its internal dynamics. 
Therefore, our research focuses on the identification of opportunities for improving the existing health facilities according to the new concepts related to green hospitals. As 'green is more than just energy efficiency' [4], we deal with the study of various aspects as the site and its environment, better access, efficient management of resources (particularly water and energy), waste reduction, use of renewable and low emission materials, as well as all factors in design that can improve the users' wellness. Some decisions must be taken at the early phases of planning, design and construction, while other can be reached when hospitals are already operating. In addition, some decisions affect the buildings and their sites (the ecological footprint of the facility), while other extend to the neighbouring communities (districts, and municipal infrastructures and services) in order to diminish the risks and to protect natural resources. Decisions can even affect wider ranges (as supplies and purchasing, for instance) and can help the efficient management while reducing the environment degradation.

In short, when starting to assess the current situation of the existing public hospitals, rather than just considering indoor qualities we also found interesting to focus on the needs and activities of all users - patients, staff and others - and on their wellbeing conditions, as well as to consider the site and the surrounding communities in order to improve environmental quality.

\section{METHODOLOGY}

We apply an evidence-based design approach, which emphasises credible evidence to influence design. And as a user's-centered approach where 'everyone counts', the research can provide a set of guidelines to improve patient and staff wellbeing, patient healing, stress reduction and safety.

On the other hand, our project assumes some factors that are included in the hospital strategic planning, as the expected demographic trends, the neighbouring population needs, the existing health services and other healthcare organisation's policies.

The project is structured in several stages that study both indoor and outdoor healthcare spaces. In this paper we deal only with the last ones and with the site influence, in order to provide a supportive environment.

Main issues considered in the methodology are detailed in the following paragraphs.

\subsection{The need of an integrated design}

The main goal is to enhance building performance by integrating exterior design elements through recognising relationships between systems and disciplines.

Achieving an effective sustainable design requires a collaborative process engaging the multiple design disciplines, as well as users, construction managers, contractors and facility managers. The merging of ideas, perspectives and areas of expertise facilitates by an open communications process to harvest multiple benefits, as the project team moved from the optimisation of single systems in isolation, to the optimisation of the entire building enterprise [5]. Establishing vertical support throughout the organisation helps to ensure success.

\subsection{A respectful site design}

The construction or renovation of a building inevitably causes interferences that affect the health of the local ecosystems. Good site design recognises the ecological integrity of a site, and pursues strategies that minimise disruptions, such as erosion and habitat displacement, by contributing to site restoration. 
Accordingly, among the main goals are to maintain and restore site biodiversity, to minimise site development and management footprint, to integrate design and orient building to take advantage of local micro-climate for heating, cooling, shading, ventilation and daylight, to eliminate intrusions on neighbour's privacy, to reduce storm water run-off, to eliminate toxic chemicals application, to optimise design for the local micro-climate reducing dependence on mechanical systems for building operations, to reduce reliance on single-occupancy vehicles, and to reduce development impact on nocturnal environments.

On the other hand, major changes taking place on the site can affect the existing and proposed site boundaries, buildings and services, location and function of disposal sites and other facilities (mortuaries, main engineering plant ...).

Site location should reflect a consideration to lessen the ripple effect of the building on the surrounding community, by enabling easy access by healthy transportation modes such as walking, bicycling and mass transit. As the site must be convenient both to the community and to service vehicles - including fire appliances, ambulances and other emergency vehicles - a particular attention must be paid to access and easy circulation for patients, staff and visitors - disabled and non-disabled - on foot, on bicycles, in cars or on public transport.

Understanding the building as a series of flows enables the physical structure of the hospital to achieve a good fit.

\subsubsection{Key considerations for developing site study and analysis}

Site information requires collecting data from the regional and environmental contexts and from site elements and influences.

The study and analysis of the regional context includes a local area plan, the knowledge of planned future changes and existing developments in the surrounding area, the existing landscapes and green spaces, the potential for new uses on site and their potential regional demand, the competing projects and other examples of similar quality standards.

Environmental considerations must involve the ecological issues, the existing and potential areas of environmental value and potential noise mitigation requirements.

The study and analysis of the site context is based on the comparison of site photos, aerial photographs and key plan. Site levels and topography, together with ground conditions including hydrological conditions - become essential information, as well as access and existing roads, transport access, services and infrastructures and other subjects as existing trees or landscape values.

Existing buildings must be also considered, together with their clinical functionality and adjacencies, connectivity and accessibility. Flexibility, adaptability and suitability for a new proposed function or need must be also studied. And standardisation of space and elements will help to reach a sustainable design proposal.

As the site of any healthcare facility must be convenient both to the community and to service vehicles, other aspects related to their maintenance requirements, fire safety and strategy and security should be considered.

\subsection{Water efficient design}

Water efficient design strategies must balance water quality and quantity demands within a building and are responsive to the watershed's capacity as source and sink. Public works projects, such as treatment plants and sewage systems, are unable to adequately remove or process the toxic materials that infiltrate these systems, potentially threatening public health. 
It is important to take a systematic look to identify potential water sources, how water is used in the building, and how it flows around the building site to reduce water usage and wastewater discharges. One target must be to minimise the use of potable water while conserving water quality and availability, as well as off site treatment of wastewater, and storm water release from the site.

On the other hand, the use of on-site water resources - rainwater, greywater - must be maximised, matching water quality with end use requirements.

\subsection{Energy efficient design}

The burning of fossil fuels is the largest contributor to global climate change and to a host of toxic emissions that impair the environmental health of directly affected communities. It is necessary to understand how to best assure a comfortable healthy indoor and outdoor environment supportive of patient recovery with a significantly reduced energy demand.

To take a comprehensive, systematic look at the building [6] and site's energy flows in order to reduce energy bills, and to evaluate opportunities for reliance on renewable energy sources, will help to improve environmental health outcomes.

Aiming to reduce the building energy demand, emissions, and reliance on energy generated by fossil fuels, goals focus on maximising the use of energy generated by renewable sources.

\subsection{Sustainable materials, construction practices and products}

The construction process affects every facet of design, from site, to materials, to mechanical systems, to indoor environmental quality and to waste generation. Construction practices have a significant direct impact on the health of the local environment during construction and will determine if the building achieves its long term health and sustainability goals.

On the other hand, the use of sustainable materials can significantly enhance a building's environmental health performance, enhances the health of habitats and increases biodiversity. Therefore, it is important to review material specifications to eliminate those that contribute to harmful health affects.

Among major goals are reduction of resource depletion, embodied energy, toxics generated throughout the life cycle of materials and waste. Impacts of reuse or disposal of building should be also minimised.

\subsection{Other issues: Signage, waymarking and navigation}

We are conscious that wayfinding is an important cause of stress among hospitals' users.

Signage, colours and finishes affect particularly low vision population, which uses to frequent healthcare facilities. As a consequence, sources of light, materials and surfaces, receptors of direct or reflected light, and responses to the signals from the receptors, must be carefully taken into account [7].

\section{CASE STUDY}

The research involves the study of four major Spanish public hospitals that are located in Madrid and its surrounding area: the Hospital Central de la Defensa Gómez Ulla in Madrid, the University Hospital Ramón y Cajal, also in Madrid, the University Hospital Príncipe de Asturias in Alcalá, and the University Hospital in Guadalajara. 
Although all of them are University Hospitals and provide world-class clinical services, each one serves to a population with different characteristics, and responds to different healthcare needs (Table 1).

As a particular case study we chose the University Hospital Príncipe de Asturias because it is located in an interesting environment outside the town and shows many possibilities for expansion and outdoor planning and design.

\subsection{The University Hospital Príncipe de Asturias}

This hospital is the specialised health facility for the population of the neighbouring municipalities of Alcalá de Henares that are located within a radius of $12 \mathrm{~km}$.

It is $33 \mathrm{~km}$ far from Madrid, and $1.5 \mathrm{~km}$ from the city centre of Alcalá, and is placed at the University Campus on a flat terrace at the north east of the town.

The Hospital is well communicated, as it is already connected with Madrid and Alcalá by means of near public transport routes, various bus lines and railroad, and it is encircled by an access road for both public and private transport.

From the typological point of view, it is an isolated flat roofed six storey building symmetrically structured into two main blocks, oriented north east and south west, respectively, that are interconnected by means of four corridors.

The hospital is surrounded by a garden that is currently crossed by access roads and used as parking areas (Fig. 1).

Table 1: Hospitals' main characteristics. (Source: Chías and Abad)

\begin{tabular}{|c|c|c|c|c|c|c|c|}
\hline $\begin{array}{l}\text { Hospital } \\
\text { Name }\end{array}$ & Year & $\begin{array}{l}\text { Nr. of } \\
\text { Beds }\end{array}$ & $\begin{array}{l}\text { Site } \\
\text { surface } \\
\mathrm{m}^{2}\end{array}$ & $\begin{array}{l}\text { Built } \\
\text { surface } \\
\text { m }^{2}\end{array}$ & $\begin{array}{l}\text { Population } \\
\text { served }\end{array}$ & $\begin{array}{l}\text { Services } \\
\text { provided }\end{array}$ & Typology \\
\hline $\begin{array}{l}\text { Hospital } \\
\text { Central de } \\
\text { la Defensa } \\
\text { Gómez Ulla }\end{array}$ & $\begin{array}{l}1896 \\
1941 \\
1972 \\
\text { (ext.) }\end{array}$ & 520 & 180,000 & 170,718 & 99,132 & $\begin{array}{l}\text { World-class } \\
\text { medical ser- } \\
\text { vices }\end{array}$ & $\begin{array}{l}\text { Tower with } 24 \\
\text { storeys, and } \\
\text { some small } \\
\text { pavilions }\end{array}$ \\
\hline $\begin{array}{l}\text { Hospital } \\
\text { Universita- } \\
\text { rio Ramón y } \\
\text { Cajal }\end{array}$ & 1978 & 891 & 67,738 & 205,900 & 566,445 & $\begin{array}{l}\text { World-class } \\
\text { medical ser- } \\
\text { vices }\end{array}$ & $\begin{array}{l}\text { Tower with } 17 \\
\text { storeys }\end{array}$ \\
\hline $\begin{array}{l}\text { Hospital } \\
\text { Uiversitario } \\
\text { Príncipe de } \\
\text { Asturias }\end{array}$ & 1986 & 594 & 84,379 & 81,930 & 241,703 & $\begin{array}{l}\text { World-class } \\
\text { medical ser- } \\
\text { vices }\end{array}$ & $\begin{array}{l}\text { Tower with } 6 \\
\text { storeys }\end{array}$ \\
\hline $\begin{array}{l}\text { Hospital } \\
\text { Universitario } \\
\text { de Guadala- } \\
\text { jara }\end{array}$ & $\begin{array}{l}1982 \\
2007 \\
2018 \\
\text { (ext.) }\end{array}$ & 771 & 45,024 & $\begin{array}{l}60,101 \\
124,768\end{array}$ & 83,633 & $\begin{array}{l}\text { World-class } \\
\text { medical } \\
\text { services }\end{array}$ & $\begin{array}{l}\text { Tower with } 10 \\
\text { storeys, and } \\
\text { enlargement }\end{array}$ \\
\hline
\end{tabular}




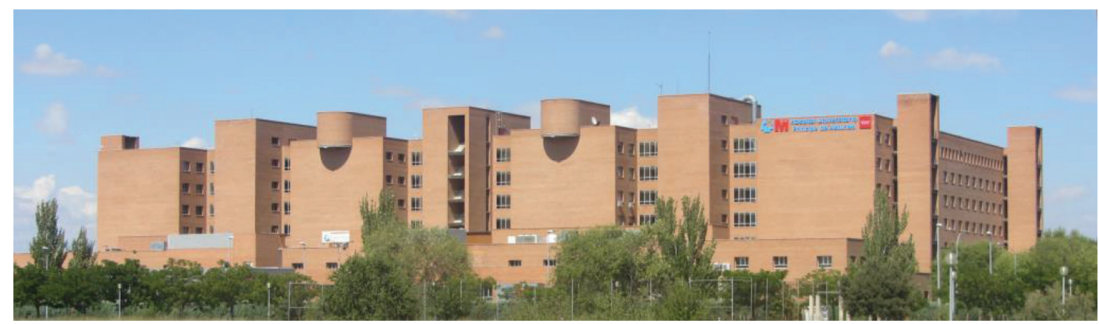

Figure 1: The University Hospital Príncipe de Asturias, Alcalá de Henares. (Source: Hospital Universitario Príncipe de Asturias)

At the south side of the site there is an adjacent lot that provides a potential option for expansion. This lot can be assigned in the current urban planning for surface parking uses (Fig. 2).

Main guidelines and proposals to be applied for a green hospital planning and design can be classified into various issues as considered in the methodology.

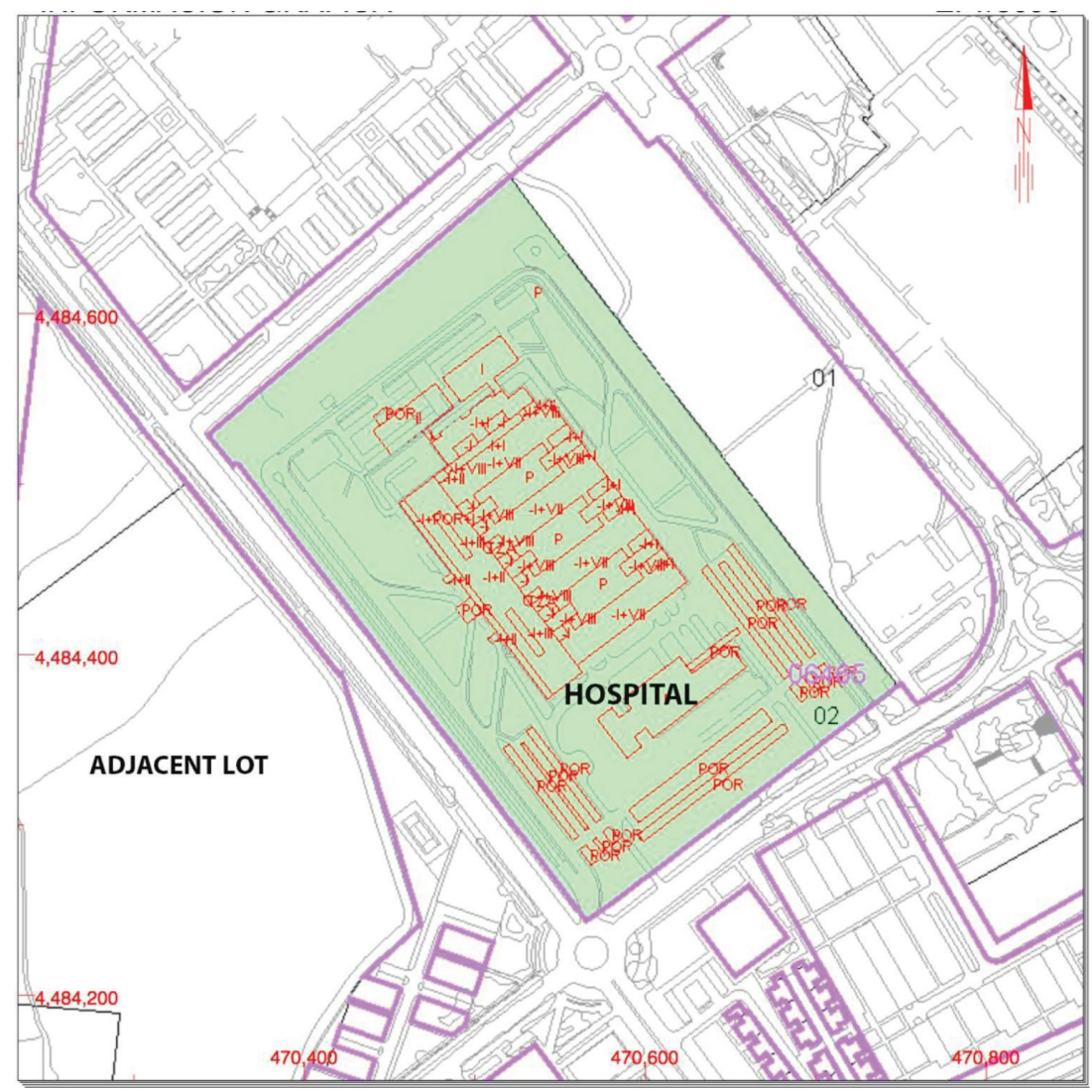

Figure 2: Cadastral plan of the University Hospital, original scale 1:5,000. (Source: Ministerio de Hacienda y Función Pública, Dirección General del Catastro 2017) 


\subsubsection{Suggested actions for an integrated design}

Along the whole planning and design processes an environmental health vision statement for the project is being developed. This goal can be reached by engaging staff, contractors, user groups and community groups, bringing them in to the design process and educating them on the benefits of green design. The use of cross discipline design, decision making, and collaborative planning and design sessions can be a good strategy.

If so, commitments to environmental health and community responsibility will be reinforced.

\subsubsection{Proposed actions for site expansion and outdoor environment arrangement}

An accurate evaluation of neighbouring brownfield sites was previously developed in order to determine a new appropriate use. In the case study, the lack of use of the adjacent western lot favoured an expansion of the Hospital's site, to be used for new zoned parking areas far from the main building.

As soon as the traffic will be taken out of the site, the surrounding areas will be free of the pressure of cars and parking areas, and new gardens, landscaped areas and orchards for in-patients can be developed. We found essential to maximise the preservation and restoration of biodiverse open space and habitat, and accordingly native trees, shrubs and plants are to be used. The use of vegetation and other shading techniques can assist passive cooling and ventilation of buildings and public and paved areas.

We also propose a design of interior and exterior lighting such that zero direct beam illumination leaves the building site.

This measure will drastically reduce the hard paved surfaces and minimise impervious cover by using open-grid and pervious paving materials. Erosion and run off into sewer systems and air pollution will be also reduced.

Our strategies will also improve the quality of outdoor air in the environment of the healthcare facility and has outstanding stress reducing qualities (Fig. 3).

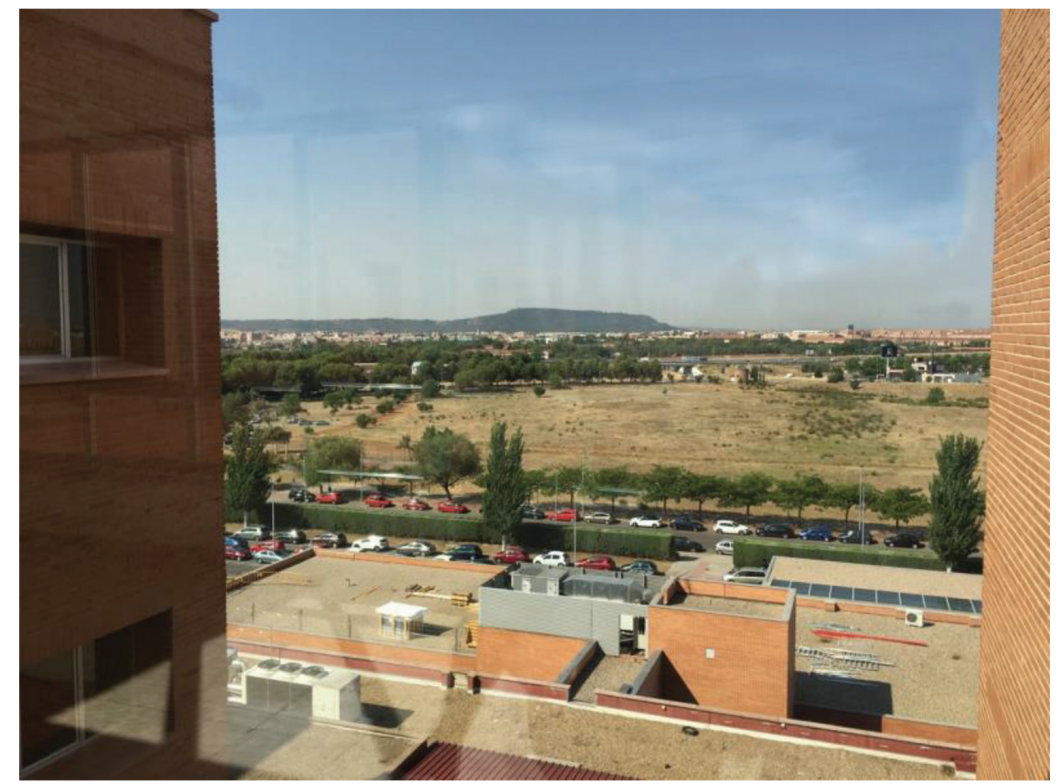

Figure 3: View of the adjacent western lot from the 6th storey of the Hospital, which is proposed to be used as zoned parking areas. (Source: Chias and Abad, June 2017) 
Proximity to public transport options as bus and railroad is a great advantage facing to establish a transportation plan that can support alternatives to fossil fueled single occupancy vehicles. An external ring will permit private car access and parking, avoiding interferences with alternative transport systems and pathways. Reduction of road size will also limit the total paving and other site disturbance.

Sustainable transport measures should be included in a transport plan, aiming to reduce the demand on parking at the site. Thus, nearby transit access there will be located a new carpool parking, bike compounds, electric car charging and other facilities for alternative vehicle fueling. A public park-and-ride area can be connected to the main building of the hospital by means of an electric bus-shuttle (Fig. 4).

As we consider the building and its environment as a series of flows, dedicated blue-light routes and a discrete segregated access for goods vehicles to receiving and delivery areas must be defined. Short-term parking bays and parking areas for disabled people must be located near the main entrance or the out-patient facilities.

Finally, in order to take profit of existing buildings and infrastructures by means of reuse and renovation should be a priority. As an example, they can become secure cycle hubs.

\subsubsection{Improving outdoor water use}

According to the proposed plan, among the strategies for improving outdoor water use are:

- To choose native plants that are tolerant of local climate, soils and water.

- To install drip irrigation and highly efficient irrigation control with moisture sensors and weather based controllers.

- To implement appropriate, safe strategies to recycle site waste water, gray water or condensate, and/or use municipal secondary treated water for irrigation and sewage

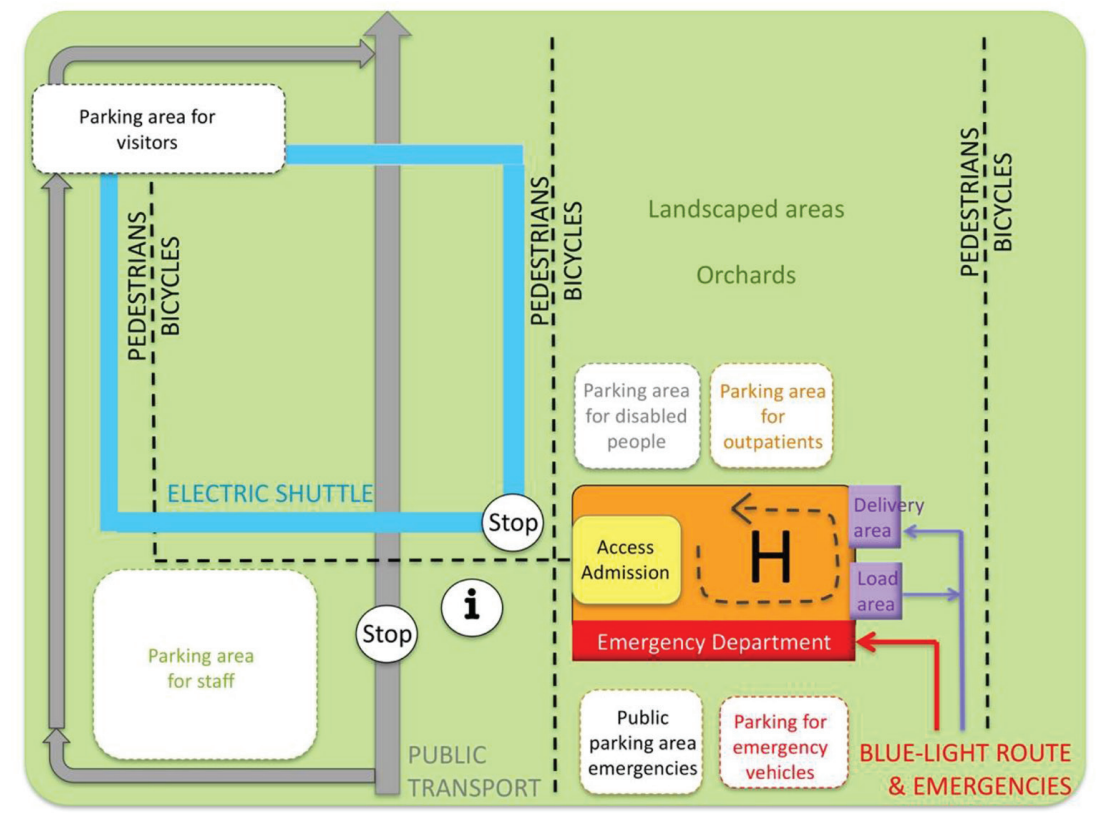

Figure 4: Proposed site plan after expansion. Strategies for a new access and parking areas. (Source: Chias and Abad) 
conveyance. Storm water runoff can be collected from roofs and site, and used for irrigation, sewage conveyance, or recharge in to acquifer.

- To minimise hardscapes by installing permeable paving and other pervious surface materials.

When possible, it is interesting to create wetlands and other systems to locally recharge underground water flows.

Sustainable orchards for particular inpatients are proposed as a part of the therapy and search for wellbeing. Support will be provided by the already existing Botanic Garden and public orchards of the University of Alcalá, that are located just $200 \mathrm{~m}$ far from the Hospital.

\subsubsection{Designing for energy efficiency}

Energy efficient design focused on the feasibility of cogeneration with the factories located in the neighbouring municipalities.

As a particular measure we propose an acknowledge with the Mahou Brewery - that is located in Azuqueca de Henares, $12 \mathrm{~km}$ far from the Hospital, in order to save energy by means of sharing a co-generation plant that takes profit of the brewery's waste. A precedent can be found at the Gundersen La Crosse Clinic, Wisconsin (USA).

This kind of strategies proved to be particularly interesting when implemented together with the adequate hospital's waste management.

We will also evaluate the use of other renewable energy systems, such as photovoltaics, wind or biomass.

3.1.5 Strategies for the use of sustainable materials, construction practices and products It is interesting to reuse existing structures when possible, and recycling of construction, demolition and land clearing debris. In our case study, these measures will be applied after the demolition of inner roads and parking areas, and the corresponding waste management plan for separation and recycling or reuse of construction, demolition and land clearing debris, and a proper disposal of residual materials will be implemented.

Work phases will be sequenced in order to minimise impacts on habitat, and on outdoor and indoor air quality.

We encourage the use of materials free from toxic chemicals and that do not release toxic byproducts throughout their life cycle, as well as materials and products that are recycled, reused, remanufactured, sustainably harvested, or obtained from local sources.

We foster design for efficient material use, by choosing durable materials, easily reusable, recyclable, compostable, or otherwise biodegradable on disposal, and that do not require toxic materials to be maintained or operated.

At last, adaptability of outdoor design according to changes in users' needs or in master planning becomes essential. It implies to prioritise some particularly sensitive areas -access, outdoor walkways, dedicated parking areas, etc.

\subsubsection{Signage and outdoor navigation}

Signage, waymarking and navigation play an essential role in the users experience of the hospital. There are many options to improve this experience, as:

- Ensuring their journey is as straightforward as possible.

- Avoiding confusing or contradictory messages and signage.

- Giving full information about public transport and parking areas.

Later strategies will affect commissioning, operation and maintenance of outdoor spaces. 


\section{CONCLUSIONS}

Every building is a unique blend of site, program, people and budget, with a unique set of challenges and opportunities.

According to the particular needs of each hospital, a specific control plan will propose changes on the existing site boundaries, and define the adequate phasing of development in detail.

There are certain design requirements that need to be considered as they apply across the whole site. Location and access design must consider indicators of strategy for main communication routes and site-related infrastructure and engineering services. Location and function of disposal sites are not negligible either.

Finally, innovative, integrative design practices recognise that new solutions emerge from a process that engenders creative problem solving and 'thinking out of the box'.

\section{ACKNOWLEDGEMENTS}

This paper is a result of the research project (BIA2016-78893-C3-1-R), which is funded by the Spanish Ministry of Economy, Industry and Competitiveness, and the European Union.

The project team is also grateful for the help and support of the following hospitals and institutions:

- Hospital Central de la Defensa Gómez Ulla in Madrid: Santiago Coca Menchero, Mariano Martín Ortíz.

- Instituto Mixto de Investigación Biosanitaria de la Defensa: Luis M. Callol Sánchez.

- Hospital Universitario Príncipe de Asturias: Félix Bravo Sanz.

- Fundación para la Investigación Biomédica, Hospital Universitario Príncipe de Asturias: Diego Rodríguez Puyol.

- Hospital Universitario de Guadalajara: Lucio Cabrerizo García, Asís Jove.

\section{REFERENCES}

[1] General design guidance for healthcare buildings, Health Building Note 00-01; Department of Health, UK Government. Available at: www.gov.uk/government/collections/ health-building-notes-core-elements. (accessed 28 April 2017).

[2] Investing in hospitals of the future; The World Health Organization. Available at: http:// www.euro.who.int/_data/assets/pdf_file/0009/98406/E92354.pdf. (accessed 2 May 2017).

[3] Health Care at the Crossroads: Guiding Principles for the Development of the Hospital of the Future; The Joint Commission Public Policy Initiative. Available at: https://www. jointcommission.org/assets/1/18/Hosptal_Future.pdf. (accessed 4 May 2017).

[4] McLennan, J.F., The philosophy of sustainable design, Ecotone Publishing Company: Bainbridge Island, WA, 2004.

[5] Green Healthcare Construction Guidance Statement; American Society of Healthcare Engineering (ASHE), The Green Building Committee, available at: http://workplaceelements.com/wp-content/uploads/2011/11/ASHE-GreenHealthcareConstructionGuidanceStatement.pdf. (accessed 4 April 2017).

[6] Sendra, J.J., Domínguez, S., Bustamante, P. \& León, A.L., Energy intervention in the residential sector in the south of Spain: current challenges. Informes de la Construcción, 65(532), pp. 457-464, 2013.

https://doi.org/10.3989/ic.13.074

[7] Design Guidelines for the Visual Environment; National Institute of Building Sciences, available at: http://c.ymcdn.com/sites/www.nibs.org/resource/resmgr/LVDC/design guideline_visual_envi.pdf. (accessed 4 May 2017). 